\title{
Modelo de Categorização de Mediação Baseado em Registros Padronizados de Interações e Atos da Fala
}

\author{
Gustavo Schwarz', João Carlos Gluz', Agnaldo Rodrigues ${ }^{1}$ \\ ${ }^{1}$ Programa de Pós-Graduação em Computação Aplicada - Univsersidade do Vale do Rio \\ dos Sinos (UNISINOS) \\ Av. Unisinos, 950. Bairro Cristo Rei - São Leopoldo - RS, CEP: 93.022-000 \\ gustavo.sne@gmail.com, jcgluz@unisinos.br, \\ agnaldo@sapucaia.ifsul.edu.br
}

\begin{abstract}
Based on the socio-historical theory of Vygotsky, this paper discusses a model for the computational representation of social interactions in virtual educational environments. For this, it will be addressed a semantic model representing the elements highlighted in the work of Vygotsky, along it is described a multiagent system, which represents the dynamic model of this study. In addition to these two models, the following topics will be discussed: a socio-historical theory, speech acts, as well as the standard storage for educational interactions Tincan.
\end{abstract}

Resumo. Com base na teoria sócio-histórica de Vygotsky, o presente artigo aborda um modelo para a representação computacional das interações sociais educacionais em ambientes virtuais. Para isso, será abordado um modelo semântico que represente os elementos evidenciados nos trabalhos de Vygotsky, juntamente é descrito um sistema multiagentes, o qual representa o modelo dinâmico do presente estudo. Além desses dois modelos, serão abordados os seguintes temas: a teoria sócio-histórica, atos da fala, bem como o padrão de armazenamento de interações educacionais Tincan.

\section{Introdução}

A ampliação das ações para a educação a distância (EAD) é um fato que pode ser demonstrado pelos dados das últimas décadas. Com a democratização do acesso à internet, os Ambientes Digitais de Aprendizagem (ADA) tornaram-se elementos cada vez mais presentes na realidade de professores e alunos. No entanto, a utilização desse tipo de tecnologia não deve representar somente um meio para troca de informações, também é preciso mecanismos que favoreçam o processo de mediação do aprendizado. De acordo [Nunes 2009], mesmo com as vantagens encontradas nesse tipo de ambiente, alguns cuidados devem ser tomados para a obtenção do sucesso pedagógico.

Em [Medeiros and Gomes 2012] é evidenciada a importância da utilização de mecanismos de monitoramento e de análise das interações dos usuários, permitindo diagnosticar problemas ou até mesmo antecipar-se a eles. Sendo assim, no presente artigo será descrito um modelo para identificar e classificar as interações educacionais em ADAs. Para tanto, do ponto de vista das Ciências da Educação o texto está fundamentado abordagem sócio-histórica de Vygotsky.

O trabalho está dividido da seguinte maneira: após esta introdução, o tópico 2 faz um referencial teórico sobre os fundamentos da teoria sócio-histórica, assim como os atos da fala. No tópico seguinte são apresentados os objetivos e a contextualização do trabalho. Já no tópico 4 são apresentados os trabalhos relacionados. No tópico 5 é 
descrito o modelo abordado. Por fim, no tópico 6, são feitas considerações finais.

\section{Referencial Teórico}

$\mathrm{Na}$ abordagem sócio-histórica a aprendizagem é uma atividade social, onde o diálogo cooperativo permite aos participantes experimentar temas de vários pontos de vista. [Vigotsky 2007] Como o foco do presente texto são os ambientes digitais, é importante evidenciar que o diálogo aparece modelado em um formato diferente daquele encontrado nas salas de aulas presenciais, sendo possível encontrá-lo, em fóruns, chats ou em ferramentas que exerçam a função de mediação. [Vicari and Andrade 2006]

A mediação, por sua vez, é um processo dinâmico onde estão presentes ferramentas (externas ao sujeito) e signos (internos), os quais servem de base para desenvolvimento Processo Psicológicos Superiores (PPS) através da internalização. A ação de mediação é desenvolvida pela interação social entre os indivíduos, os quais, apropriando-se dos instrumentos de mediação, buscam modificar o meio ou o comportamento (seu ou de outra pessoa). Em [Passerino 2005] é possível encontrar uma classificação dessas ações de mediação, sendo elas: controle, autocontrole $\mathrm{e}$ autorregulação.

O controle é externo ao sujeito e é guiado pelo par mais experiente. Está divido em: i) controle direto (ordens, diretivas e perguntas diretivas); ii) controle indireto (perguntas perceptivas, perguntas conceituais, gratificação, renuncia direta, confirmação passiva, afastamento físico). O autocontrole representa uma ação realizada pelo sujeito obedecendo a um tutor internalizado. Possui a seguinte divisão: i) autocontrole direto (imitação direta, modelo, fala dirigida). ii) autocontrole indireto (corresponde à fala que o sujeito dirige a si mesmo). Já a autorregulação é o plano de ação que o sujeito cria e que se converte em seu próprio tutor.

Outro ponto a ser evidenciado é que, no processo de mediação, para transmitir uma experiência de forma racional e intencional para outro, é necessário um sistema mediador, cujo protótipo é a fala humana, tendo essa o papel da comunicação, ou seja, o intercâmbio social. [Vygotsky 2008] Para realizar uma análise da comunicação, o primeiro passo é a observação da fala em si, analisando seus elementos ou estágios componentes. "Searle e Austin caracterizaram o ato de enunciação de uma frase em três tipos distintos de atos da fala: os atos locucionários, os atos ilocucionários e os atos perlocucionários." O primeiro corresponde a enunciação efetiva dos fonemas, sílabas e palavras do falante. Já o segundo compreende ao significado que o falante procura associar ao seu ato locucionário e que está tentando transmitir ao ouvinte. $\mathrm{O}$ ato perlocucionário, por sua vez, está associado aos efeitos ocasionados ao ouvinte em função da enunciação do ato da fala em si. [Searl 1979 apud. Gluz 2005]

\section{Contextualização do Problema e Objetivos}

Apesar da importância do monitoramento de interações em ADAs, a simples análise quantitativa de dados pode não ser suficiente para justificar a utilização desse tipo de tecnologia. Dizer, por exemplo, que um aluno postou um determinado número de mensagens no fórum pode não significar muito ao avaliar o estado do aluno. Por outro lado, uma análise mais detalhada do conteúdo das mensagens e de suas interações pode fornecer subsídios para entender melhor a situação do aluno.

Além disso e, conforme já descrito anteriormente, para que o indivíduo assimile um novo conceito (a internalização do conceito), ele passará pelas etapas de controle, 
autocontrole e autorregulação até ter o domínio sobre assunto estudado. No entanto, conforme aponta [Severo et al. 2010], "um dos problemas atuais dos pesquisadores sócio-históricos é acompanhar e compreender esse processo de mediação até a internalização", Tendo isso em vista, o presente artigo objetiva apresentar um modelo para a análise e classificação das categorias de mediação em ADAs.

\section{Trabalhos Relacionados}

No trabalho de [Severo et al. 2010] é desenvolvida uma ontologia para categorizar o processo de mediação com base em interações sociais. $\mathrm{O}$ autor utiliza como fundamento para o seu trabalho as mesmas categorias de mediação já apresentadas aqui (controle, autocontrole e autorregulação). Antes da criação da ontologia os autores realizaram um trabalho prévio para a identificação de características linguísticas em fóruns, portfólios, diário de bordo e correio eletrônico de um ADA e, com base nessas informações, foi elaborada a ontologia de mediação. Ressalta-se no entanto, que o trabalho trata da criação de um modelo ontológico sem deixar claro como serão inseridos os dados na ontologia.

Em [Bonacin et al. 2012] os autores também buscam representar o processo de mediação em ambientes virtuais. No entanto, o foco do trabalho é o de identificar o significado e a intencionalidade das interações sociais em ferramentas que permitem a troca de mensagens textuais. No trabalho são utilizadas as teorias dos atos fala para a criação da ontologia. Assim como no primeiro trabalho, os autores desenvolveram um modelo ontológico para a representação das interações sociais, sem descrever um modelo dinâmico que fará uso da ontologia.

Já o trabalho de [Severo et al. 2013] é realizado o acompanhamento das atividades dos alunos no ambiente Moodle, o qual busca identificar o processo de mediação naquele ambiente. Para tanto os autores utilizam de técnicas de mineração de texto para essa finalidade. Para isso os autores criaram um plugin para o Moodle. Diferentemente dos primeiros trabalhos, aqui não foi possível identificar o uso de ontologias.

Como diferencial em relação aos outros trabalhos, é proposto tanto um modelo estático (através de ontologias) como um modelo dinâmico para a representação da mediação em ADAs. Além disso, o sistema contará com um mecanismos de regras para a identificação de algumas características nas interações. Por fim, buscou-se criar um modelo utilizando padrões já existentes a fim de permitir a interoperabilidade dos dados entre diferentes ferramentas.

\section{Trabalho Proposto}

A seguir será apresentada arquitetura proposta para o trabalho, tendo como principais elementos as ontologias e uma camada dinâmica composta se agentes de software.

$\mathrm{Na}$ Figura 1, é possível observar que na camada superior está localizado ambiente de aprendizagem. Os testes serão realizados no ambiente Moodle, sendo que a coleta de interações, informações do ambiente e de dados dos usuários serão realizadas através de dois plugins. Eles serão responsáveis por acessar a base de dados do Moodle, coletar as informações e enviar os dados para os agentes que fizeram a solicitação. $\mathrm{O}$ SIOC Plugin será desenvolvido utilizando as seguintes bibliotecas: Moodle Web Service API e Moodle Data Manipulation API. Já no Tincan Plugin será utilizada, além das duas bibliotecas anteriores, a Tincan API - PHP Library [ADL 2013]. 
Na próxima camada (Agentes) é possível verificar a existência de cinco agentes. $\mathrm{O}$ "Environment Manager Agent" será responsável por fazer a comunicação com o Moodle e solicitar os dados do ambiente educacional (mensagens, perfil dos usuários, etc). Por outro lado, o agente "Interaction Manager Agent" será responsável buscar as informações das interações ocorridas no Moodle. Após solicitar os dados, as informações serão armazenadas nas ontologias Tincan e SIOC [Berrueta 2010].

Uma vez armazenadas as informações nas ontologias supracitadas, o agente "Mediation Status Manager Agent" será responsável por consultar as informações contidas em Tincan e SIOC e, posteriormente, identificar juntamente ao agente "Speech Acts Engine Agent" os atos da fala nas mensagens (no caso de chats, fórum e wiki). Além disso, o sistema também possuirá um agente com regras que auxiliarão na catalogação dessas categorias de mediação.

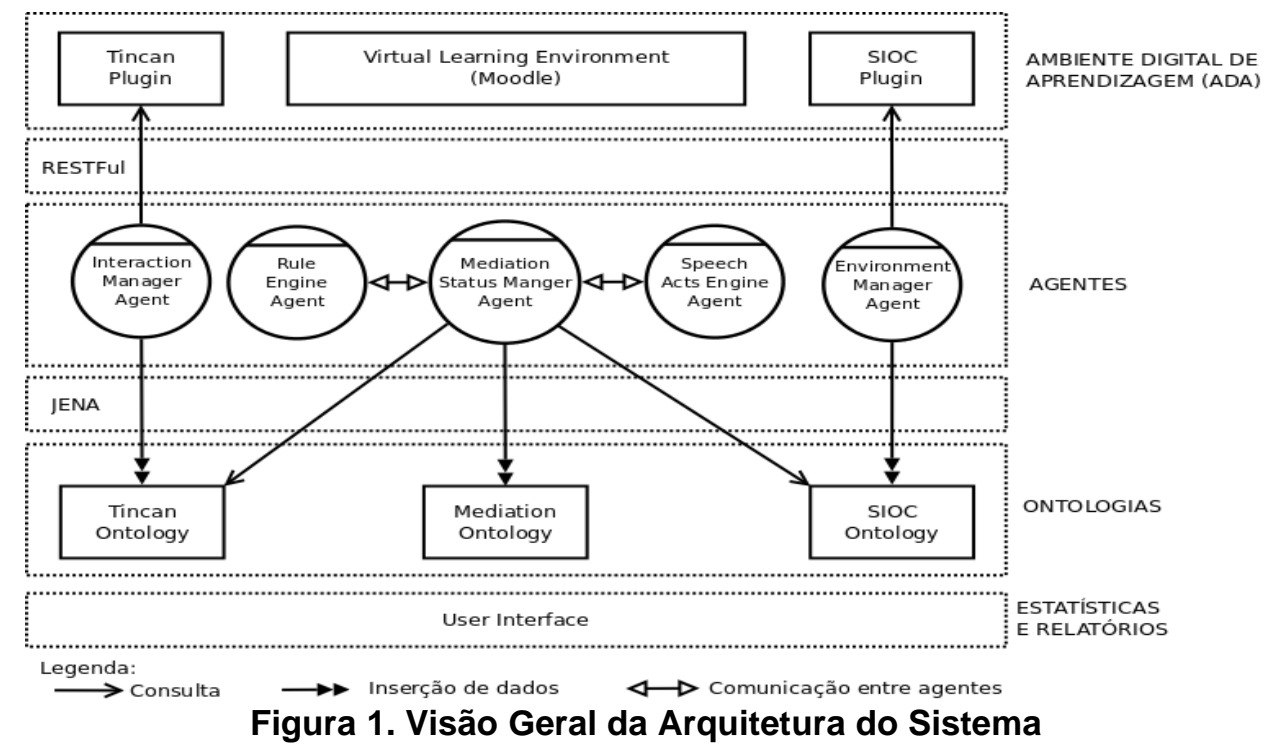

Por fim, será fornecida uma interface para que os usuários possam visualizar informações sobre o processo de mediação ocorrido no ADA. Sendo que relatórios e gráficos apresentarão tais informações.

\section{Considerações Finais}

Mesmo que algumas teorias pedagógicas tenham surgido antes da utilização de computadores no ensino, nem por isso elas devam ser menosprezadas quando o tema é o aprendizado à distância, bem pelo contrário, para que haja harmonia entre o digital e o presencial, é preciso o correto emprego delas.

Com o aumento da procura pelos cursos EAD, a tarefa de monitorar e analisar manualmente as interações dos alunos torna-se uma tarefa bastante dispendiosa. Dessa forma, o presente artigo apresenta um modelo que permite fornecer informações do processo de mediação em um ambiente virtual.

Com diferencial em relação aos outros trabalhos, o artigo aqui apresentado fornece um modelo (estático e dinâmico) para a classificação do processo de mediação baseado nos atos da fala. Também é utilizado um padrão de catalogação das interações (Tincan), permitindo que os dados gerados possam ser utilizados entre diferentes mecanismos de análise de dados.

A validação do modelo será realizada em uma turma na qual os dados sobre 
interações e mensagens dos participantes já foram coletados. O próximo passo é o processamento destes dados e a posterior validação das informações junto ao professor responsável pela turma.

\section{Agradecimentos}

Agradecimentos ao CNPq por ter proporcionado o financiamento dessa pesquisa.

\section{Referências}

ADL, A. D. L. (2013). Experience API. https://github.com/adlnet/xAPI-Spec, [accessed on Jul 20].

Berrueta, D., Brickley, D., Decker, S., et al. (25 mar 2010). SIOC Core Ontology Specification. http://rdfs.org/sioc/spec/, [accessed on Jul 20].

Bonacin, R., Dos Reis, J. C., Hornung, H. and Baranauskas, M. C. C. (jun 2012). An Ontological Model for Representing Pragmatic Aspects of Collaborative Problem Solving. In 2012 IEEE 21 st International Workshop on Enabling Technologies: Infrastructure for Collaborative Enterprises (WETICE).

Gluz, J. C. (2005). Formalização da comunicação de conhecimentos probabilísticos em sistemas multiagentes : uma abordagem baseada em lógica probabilística. Universidade Federal do Rio Grande do Sul (UFRGS).

Medeiros, F. P. A. De and Gomes, A. S. (2012). Monitoramento da Experiência do Usuário em Ambientes Colaborativos Virtuais de Aprendizagem: Um Mapeamento Sistemático. Anais do Simpósio Brasileiro de Informática na Educação, v. 23, n. 1.

Nunes, I. B. (2009). A história do EAD no mundo. In: Litto, F. M.; Formiga, M.[Eds.]. Educação a Distância: O Estado da Arte. São Paulo: Pearson Education do Brasil. p. 2-8.

Passerino, L. M. (2005). Pessoas com autismo em ambientes digitais de aprendizagem: estudo dos processos de interação social e mediação. Universidade Federal do Rio Grande do Sul (UFRGS).

Severo, C. E. P., Passerino, L. M., Koch, S. H. da S., Maciel, M. and Glus, J. C. (9 jun 2010). Uma ontologia para categorias de mediação segundo uma abordagem epistemológica baseada na interação social. RENOTE, v. 7, n. 3, p. 368-378.

Severo, C. E. P., Passerino, L. M. and Lima, J. V. De (2013). Mapeamento de Indícios de Mediação em Ambiente Virtual de Ensino e Aprendizagem por Meio de Um Sistema de Mineração de Textos. Anais do Simpósio Brasileiro de Informática na Educação, v. 24, n. 1 .

Vicari, R. M. and Andrade, A. F. (2006). Construindo um ambiente de aprendizagem a distância inspirado na concepção sociointeracionista de Vygotsky. Educação Online: Teorias, práticas, legislação e formação corporativa. Edições Loyola. p. 257-274.

Vygotsky, L. S. (2008). Pensamento e Linguagem. Martins Fontes. 